\title{
DOCUMENTOS
}

\section{Los pastiches huguescos de Gutiérrez Nájera}

En el "Homenaje a Manuel Gutiérrez Nájera" de la Revista Mexicand de Literatura (nuevo época, No. 2, abril-junio de 1959, pp. 206, 2I3) me referí extensamente a los pastiches de Víctor Hugo forjados por el precursor mexicano del modernismo, y en especial a la oda "En el "Campo de Marte" (al prepararse la Exposición Universal), cuyo texto tescaté de La Voz de España, 3 I de julio de I879, año I, No. 45, p. 3. Es el primer pastiche conocido, ausente todavía de las Poesias completas, quizá porque los editores han tomado muy en serio el repudio que Gutiérrez Nájera estampó en El Partido Liberal, 10. de abril de x888: "Allá en mis mocedades literarias, hice una oda malísima que di como traducción de Víctor Hugo, y todos cayeron en el garlito... iNo quiero morirme con este cargo de conciencia! Esa oda 'A la Exposición Universal' no es de Víctor Hugo, no puede ser de Víctor Hugo; tampoco es mía, porque yo no la quiero y me parece mucho peor que sus hermanas; son versos baldíos, versos mostrencos que yo regalo a quien los quiera". Ya que acepté condicionalmente el regalo de esa oda, estoy obligado a restituir al público otro pastiche huguesco de Gutiérrez Nájera, publicado muy incompletamente en sus Poesias completas. Se trata de "Los moscos", publicado por vez primera en El partido Liberal, 15 de octubre de 1885 , tomo I, No. 195, p. 2, y precedido de la inocente notificación: "Por el correo del cielo recibimos la siguiente composición de Víctor Hugo, que publicamos con orgullo. El estilo elevado y antitético que realzaba los 
textos franceses del poeta, lo tienen también sus versos españoles. El lector puede juzgar". Abajo el título: "Víctor Hugo y los moscos" y en seguida el texto: 47 versos ( 45 endecasílabos y 2 heptasílabos, el cuarto y el 4I), la mitad pareados, el resto de rima perfecta y uno suelto, el quinto. De los cuales sólo se conocen los 15 primeros, un poco menos de la tercera parte del pastiche.

Resulta un poco difícil imaginar que los lectores contemporáneos de Gutiérrez Nájera tomatan el pastiche con credulidad como obra del propio Hugo, no escarmentados con los antecedentes de la oda de 1789 . Se necesitaba, ciertamente, ser candoroso para leer en serio eso del "correo del cielo" (la muerte de Hugo, recientemente acaecida, fue duelo general de la prensa hispanoamericana, y la aviación todavía no aparecía) y de "sus versos españoles" (que el hispanismo de Hugo nunca llegó a escribir). Sin embargo, el caso es que el pastiche hizo fortuna entre los incautos, según lo refiere una nota anónima de la Revisto Azul, "Una humorada de El Duque Job", 5 de marzo de 1895, tomo III, Núm. r, pp. 4-5, poco después de la muerte de El Duque Job: "Hubo una época en que el inolvidable fundador de la Revista Azul era dura y acremente atacado por un grupo de gacetilleros... Por esa época a que nos referimos no aparecía verso de Manuel Gutiérrez Nájera que no fuera objeto de violentos ataques... Manuel Gutiérrez Nájera se propuso, sin embargo, armar una ratonera a sus críticos. . Dicho y hecho: una mañana - esto ocurría el año de I885- anunciaba El Partido Liberal, que entre los re. cientes canjes habían llegado los últimos versos de Víctor Hugo. . . Y reproducía a continuación el siguiente delicioso pastiche: [Aquí "Los moscos"]. Los críticos no husmearon la trampa... y la composición pasó con hiperbólicos elogios de hoja en hoja y corrió por toda la prensa de la República. Hasta que otra mañana, el verdadero autor de 'Los moscos', descubrió el enredo, que sirvió de provechosa lección a sus Aristarcos". (Como se ve, a los diez años de distancia y muerto El Duque Job el suceso tomaba visos de leyenda: la gacetilla preliminar, ya lo hemos visto, no decía nada de "recientes canjes" ni de "últimos versos de Víctor Hugo" sino que se limitaba a dar pistas falsas: "correo del cielo" y "versos españoles").

Dos años después de la publicación inicial de "Los moscos", debió de ser ya de dominio público la identidad de su autor, porque Manuel Puga y Acal en una de sus "Críticas semanarias" de El Pabellón Nacional, la dedicada al poema "A Byron", de Salvador Díaz Mirón, 23 de diciembre de 1887 , año I, No. 243 , pp. 2-3, se refiere, sin alarma, a "el 
delicioso pastiche titulado 'Los moscos', que publicó Gutiẻrrez Nảjera hace algún tiempo", y a continuación reproduce los primeros 15 versos, los mismos que reprodujo después la Revista azul en I895. Las Poesías completas, edición de Francisco González Guerrero (México, Editorial Porrúa, S. A., I953, 2 vols.; "Colección de Escritores Mexicanos" Nos. 66-67) debieron de utilizar estas fuentes al incluirlos en el tomo II, p. 349, pero no El Partido Liberal que originalmente publicó el pastiche completo, tal como aquí se trascribe:

\section{Víctor Hugo y Los Moscos}

Hizo Dios al león, al tigre hosco, y a la hiena voraz: el diablo, al mosco!

Y Arihmán, encarándose blasfemo

4 con el Creador Supremo,

5 murmuró estas palabras: "Tu obra admiro!

Tú creaste la garra, la araña horrible, el encorvado pico, el diente agudo, el pulpo, mareando en lo invisible, la hiena: boca. La culebra: nudo. El rojo tigre, un Hércules de Angola, el colmillo, el tentáculo, la uña; ese Bismarck del tiburón, la cola; y ese 2 de Diciembre, la pezuña!

"Pero tu obra es la maldad infolio,

is el elefante es casi un capitolio;

la trompa es una encina que se mueve: el oso blanco, un Ararath de nieve, los búfalos, los toros, los chacales y el mariscal Von Moltke son iguales; todo eso es rudo, material y tosco, yo ni gatras ni dientes necesito, tomo una sola gota de infinito, le infundo mi maldad, y te hago el mosco".

¿Qué es el mosco, en verdad? Es lo invisible, lo formidable, lo brutal, lo innúmero; el león tiene la garra, araña horrible!; 
pero el mosco le vence, tiene el número!, en la atmósfera azul se multiplica;

es un átomo de aire que nos pica;

no sabemos si es rojo, negro o verde, es una idea de Veuillot que muerde.

Le matamos y a poco resucita, se oculta, porque el mosco es un jesuita, pero luego zumbando se rebela:

es un microbio prófugo que vuela.

Obsesión! Ananké! Lo interminable zumbando eternamente en lo insondable!

Ser bebido! joh terror! Ser como fuente en que el mosco voraz su sed abreva y sentir que la sangre se nos lleva

$4 \mathrm{I} y$ que es nuestro pariente!

¿Qué congoja, qué angustia habrá más honda para el poeta que sentirse fonda?

No hay moscos en el cielo; el mal impera en la proscrita humanidad sombría; no hay moscos más allá, si los hubiera Júpiter inmortal se rascaría!

ERnesto Mejía SÁNCHez

Universidad Nacional Autónoma de México, Biblioteca Nacional, México. 